\title{
Título da página eletrónica: The Past is Unwritten
}

URL: https://thepastisunwritten.wordpress.com/

\section{Paula Guerra}

\section{(2) OpenEdition \\ Journals}

Edição electrónica

URL: http://journals.openedition.org/rccs/6335

DOI: $10.4000 /$ rccs. 6335

ISSN: 2182-7435

\section{Editora}

Centro de Estudos Sociais da Universidade de Coimbra

Edição impressa

Data de publição: 1 maio 2016

Paginação: 262-263

ISSN: 0254-1106

Refêrencia eletrónica

Paula Guerra, "Título da página eletrónica: The Past is Unwritten », Revista Crítica de Ciências Sociais [Online], 109 | 2016, posto online no dia 18 maio 2016, consultado o 25 setembro 2020. URL : http:// journals.openedition.org/rccs/6335; DOI : https://doi.org/10.4000/rccs.6335 


\section{Espaço Virtual}

\section{Título da página eletrónica: Keep It Simple, Make It Fast! URL: http://www.punk.pt/pt/}

O punk tem merecido cada vez mais atenção, quer a nível internacional, quer a nível nacional. Seja a partir do olhar jornalístico, seja por parte de projetos artísticos e culturais que, considerando diferentes contextos geográficos e socioculturais, tem emergido todo um conjunto de iniciativas a fim de contribuir para uma melhor e mais completa compreensão de um fenómeno que extravasa a esfera musical.

Em Portugal, desde meados de 2012, o projeto de investigação Keep it Simple, Make it Fast! (KISMIF) ${ }^{1}$ tem vindo a compilar informação e a produzir conhecimento sobre uma realidade que, de uma forma geral, é ainda pouco conhecida: a cena punk portuguesa desde a sua formação até aos dias de hoje (1977-2012). A abordagem é transdisciplinar (Antropologia, História, Psicologia, Comunicação, Jornalismo e Sociologia) e articula tempos e espaços diversos, de forma sincrónica e diacrónica, de modo a levantar o véu que oculta um objeto de estudo manifestamente complexo e socialmente pouco visível.

A plataforma digital Keep It Simple, Make It Fast! é um dos produtos deste projeto de investigação. Assenta numa lógica de partilha da informação recolhida e produzida e numa vontade de dar a conhecer a história de um fenómeno cultural tão multifacetado como o punk. É um espaço de work in progress e do-it-yourself, no sentido em que é continuamente alimentado pelos membros da equipa do projeto, mas também por todos aqueles que, possuindo textos e narrativas referentes ao trajeto do punk português, os queiram partilhar.

Para além de informações relativas ao projeto, como as referentes à equipa, às linhas de investigação ou aos produtos (destaque para o documentário produzido no âmbito do projeto - "Bastardos. Trajetos do punk português (1977-2014)"), é possível encontrar vários artigos sobre bandas, fanzines ou editoras que marcaram e continuam a marcar a história do punk, bem como referência a livros recentemente publicados e que abordam não apenas o punk, mas também outras cenas musicais underground, a nível nacional e internacional. Há também um espaço dedicado às duas edições da conferência internacional e da summer school realizadas em 2014 e 2015, no âmbito do projeto. A plataforma digital inclui ainda um link para um arquivo do punk português, que conta com digitalizações de diferentes tipos de material:

\footnotetext{
${ }^{1}$ Projeto cofinanciado por fundos nacionais através da Fundação para a Ciência e a Tecnologia (PTDC/CS-SOC/118830/2010) e por fundos FEDER (através do programa operacional COMPETE). O KISMIF é desenvolvido no Instituto de Sociologia da Faculdade de Letras da Universidade do Porto (ISIUP), em parceria com o Griffith Centre for Cultural Research (GCCR), a Universitat de Lleida (UdL), a Faculdade de Economia da Universidade do Porto (FEP), a Faculdade de Economia da Universidade de Coimbra (FEUC), a Faculdade de Psicologia e de Ciências da Educação da Universidade do Porto (FPCEUP), as Bibliotecas Municipais de Lisboa (BLX), a Raging Planet e a Anoise Records.
} 
artwork e memorabília, como bilhetes e cartazes de concertos/festivais; capas de CD, vinis, K7; fanzines; e fotografias, entre outros.

Considerando o conjunto de informações e de referências que a plataforma digital Keep It Simple, Make It Fast! disponibiliza, parece-nos que é de toda a pertinência para todos aqueles que se interessem, seja numa perspetiva de investigação, seja numa perspetiva informativa, pelo movimento punk e, em sentido mais amplo, pelas culturas urbanas e suas manifestações musicais. Ao mesmo tempo, o seu caráter colaborativo parece-nos um bom exemplo de aproximação entre a academia e a sociedade em geral, ao promover a partilha e o acesso ao conhecimento produzido, e também o diálogo entre vivências distintas mas complementares.

Ana Sofia Oliveira

\section{Título da página eletrónica: PROFestival URL: http://profestival.net/}

Os festivais têm vindo, nas últimas décadas, a assumir uma crescente relevância nas estratégias de desenvolvimento socioeconómico de cidades e regiões, estando frequentemente associados a estratégia de marketing urbano e territorial. Na verdade, atualmente assiste-se a um crescente fenómeno de "festivalização da cultura" que se carateriza não só pelo seu caráter global mas também pela sua profunda variedade e diversidade, abrangendo as mais diversas áreas artísticas, culturais, lúdicas e criativas em sentido cada vez mais amplo.

O PROFestival constitui uma plataforma digital que foi desenvolvida no âmbito do Programa de Mestrado em Gestão Cultural da Universidade de Barcelona e é gerida pela Fundação Bosch i Gimpera (que está associada à Universidade de Barcelona). Conta ainda com o apoio do Ministério da Educação, Cultura e Desporto de Espanha, do Instituto de Cultura de Barcelona e Ibertur, bem como com a colaboração de vários diretores, programadores e outros profissionais ligados à organização de festivais.

Neste website pretende-se, por um lado, promover os festivais artísticos (de música, artes visuais, artes performativas, literatura, etc.), no plano nacional e internacional.
Para tal, o PROFestival disponibiliza um mapeamento georreferenciado de festivais que se realizam em Espanha, que constitui um poderoso motor de busca, uma secção dedicada à oferta de programação de festivais, um calendário de eventos e publica ainda, com regularidade, um boletim informativo. Além disso, este portal online tem ainda associado um blogue onde são regularmente disponibilizados artigos, entrevistas e outro tipo de notícias relacionadas com o universo de festivais e com as transformações associados ao processo de "festivalização da cultura", a que anteriormente aludíamos, refletindo detalhadamente acerca dos desafios que se colocam à gestão cultural e aos processos de formação dos profissionais do setor cultural e criativo.

O PROFestival procura ainda, por outro lado, contribuir para melhorar as condições de trabalho dos profissionais do setor (programadores, produtores, técnicos, assessores de comunicação, etc.), disponibilizando o acesso a um conjunto de "ferramentas" técnicas disponível numa área reservada a profissionais: bases de dados, boletins informativos, ofertas de emprego e outros recursos (bibliografia, vídeos, estudos e estatísticas, etc.). De forma 
geral, a informação acessível neste portal encontra-se bastante bem organizada, dando a possibilidade de os utilizadores fazerem uma pesquisa dinâmica, na medida em que permite uma busca por diferentes "pontos de entrada": o nome do festival, a sua tipologia, a localização geográfica ou ainda através de palavras-chave. Embora parte da informação esteja disponível apenas a quem se inscrever como profissional, qualquer leitor tem a possibilidade de aceder a um conjunto bastante interessante de informações relacionadas com a diversidade de oferta de festivais, as suas características, audiências, etc. Considerando o conjunto de informações e de referências que o PROFestival disponibiliza, tendo sobretudo por referência o universo de Espanha, parece-nos que este constitui um motor de busca digital com grande interesse para todos aqueles que se interessem, quer numa perspetiva de investigação, quer numa perspetiva lúdica, pela temática dos festivais e, em sentido mais amplo, das cidades e culturas urbanas.

Pedro Quintela

\section{Título da página eletrónica: Dangerous Minds URL: http://dangerousminds.net/}

O espaço virtual Dangerous Minds apresenta-se como um compêndio de "novas e estranhas" ideias, novas formas de arte, novas abordagens a questões sociais e novas informações/notícias relacionadas com a cultura $p o p$ em geral emergente depois da Segunda Grande Guerra. Com uma atividade diária de aproximadamente quatro posts, este espaço assume como missão a seguinte: "Achamos que os seres humanos são muito estranhos e muitas vezes totalmente hilariantes. Nós gostamos muito de coisas estranhas e inexplicáveis. Nós acreditamos que as coisas têm de mudar e rapidamente. Tem de ser algo acerca do bem comum, senão não interessa. Nós gostaríamos de pedir sugestões acerca de coisas engraçadas/sérias aos nossos leitores de elevado nível de inteligência. Nós somos a vossa distração favorita." (https://www. facebook.com/DangerousMindsBlog/ timeline). Assim, sob o turbilhão da cultura pop, este espaço permite um mergulho diário constante nas suas manifestações, concretizando uma tarefa bem difícil: a de disseminar acontecimentos, artefactos e vidas marcadas por forte volatilidade, velocidade e efemeridade.
Atualmente, conta com o contributo de 16 pessoas que, com maior ou menor regularidade, escrevem sobre aqueles que são os seus interesses e sobre aquilo que de mais peculiar tiverem conhecimento na esfera da cultura pop. A ideia base não é uma espécie de recomendação dos artigos ou dos temas visados mas, antes, a disponibilização da informação e uma simples chamada de atenção sobre a mesma. E, como é habitual, a narrativa combina acasos e predestinações, ortodoxias e dissidências, coisas que foram novas e envelheceram, coisas que estavam perdidas e foram recuperadas, memórias, saberes e emoções, numa constante elaboração e reelaboração, intertextualidade e interpretação.

A função de arquivo assumida por este espaço é da máxima importância. Assim, num arquivo que remonta a maio de 2009 , podemos encontrar inúmeros artigos/publicações que se enquadram num variado leque temático, abrangendo uma panóplia de 53 tópicos relevantes para as culturas urbanas, tais como: a girl's best friend is her guitar, activism, advertising, advertorial, american-style (Republican) Christianity, amusing, animals, animation, art, belief, 
books, class, war, crime, current events, dance, design, drugs, economy, fashion, featured, feminism, food, games, heroes, hip-bop, history, bysteria, idiocracy, kooks, literature, media, movies, music, occult, one-bit wonders, politics, pop culture, punk, queer, ri.p., race, science/tech, sex, sports, stupid or evil?, superstar, television, the wrong side of history, they hate us for our freedom, thinkers, unorthodox. O tipo e a profusão de tópicos traduzem bem o seu propósito, sistematizado da seguinte forma: "Dangerous Minds é uma compilação do novo e do estranho - novas ideias, novas formas de arte, novas abordagens a questões sociais, e novas descobertas da cultura pop. A nossa política editorial, como a definimos, faz com que muitas vezes os conteúdos reflitam os interesses, as vontades e as peculiaridades de cada autor que contribui. Mas isso é relativo: muitas vezes a ideia é apenas 'Isto foi o que tal e tal disseram, deem uma olhada e digam o que pensam'. Isso é importante: nós não defendemos tudo aquilo que está aqui presente; estamos sobretudo a dizer 'Aqui está'." (https://www.facebook.com/ DangerousMindsBlog/timeline).

Paula Guerra

\section{Título da página eletrónica: The Past is Unwritten URL: https://thepastisunwritten.wordpress.com/}

A música e as diferentes cenas musicais, assim como as suas implicações em diferentes esferas da sociedade, têm vindo a adquirir uma importância crescente que se traduz, entre outros aspetos, na proliferação de trabalhos científicos sobre as mesmas. A criação do blogue The Past is Unwritten é reflexo disso mesmo, como deixa antever o seu subtítulo: "Digging Through the History of the American Underground Music Scene". O blogue, que funciona como uma espécie de fanzine online, foi criado, no início de 2010, por Rylan Kafara durante a sua investigação no âmbito de um mestrado em História Americana. O principal objetivo era, na altura, contribuir para uma mais completa e matizada compreensão acerca das cenas musicais americanas no espetro do punk e do que é considerado música underground, alternativa e independente, atendendo igualmente às suas implicações sociais, culturais e políticas. Ao desenvolver uma tese sobre um tópico em relação ao qual toda a gente sabe algo e tem uma opinião, Rylan Kafara considerou ser uma boa ideia ter um blogue onde todos pudessem partilhar a informação que possuíam, assim como trocar experiências e discutir opiniões. Simultaneamente, esta era uma forma de reconhecer as ideias e o conhecimento das pessoas. Nas suas próprias palavras: "A intenção deste blogue é trabalhar na atmosfera de um 'entendimento nuanceado', em especial no que toca às cenas punk/ I underground/alternativas/independentes, e às suas implicações sociopolíticas e culturais. Estou a escrever a minha tese para um mestrado em História Americana sobre esse assunto, e já que é um tópico de que toda a gente sabe alguma coisa, e muito provavelmente, sobre o qual toda a gente tem uma opinião, achei que era uma boa ideia para um blogue. Assim, posso 'roubar as ideias' das pessoas e ficar com um curso à custa disso... quer dizer, citar, obviamente, citar cuidadosamente as pessoas que expressam as ideias, dando-lhes o devido crédito e reconhecimento, garantindo o respeito pelo seu esforço. Obviamente." (https://thepastisunwritten.wordpress. com/about/). 
Hoje a tese, intitulada "This is Not For You: The Rise and Fall of Music Milieux in Seattle and the Pacific Northwest, 1950s-1990s", está terminada e defendida, mas o interesse e a investigação em torno da música, da cultura pop e da história prevalecem, o que justifica a manutenção do blogue. Para além do livre acesso à tese e às publicações do autor, encontramos referências a outros espaços virtuais relacionados com o tema, bem como artigos a respeito do underground, do punk e da sua dimensão política e de resistência ou sobre a cena musical local (Edmonton, Alberta, Canadá).

Quanto ao nome, por um lado é uma home-nagem a Joe Strummer e à sua ideia "the future is unwritten". Por outro lado, é o reiterar de que esta ideia pode ser aplicada também ao passado. Assume-se que as ideias e as opiniões sobre "o que realmente aconteceu” na História constituem algo aberto ao debate e ao confronto de interpretações. Contrariando a crença popular, o "quê" e o "quando" podem ser menos importantes do que o "como" e o "porquê". Neste sentido, novas e diferenciadas informações podem contribuir para uma compreensão matizada, e por isso mais completa, do passado. É, essencialmente, nesta premissa que assenta o blogue The Past is Unwritten: na partilha de gostos, de memórias, de afinidades, de interesses, de emoções - como tem acontecido um pouco por todo o lado com as publicações independentes.

Paula Guerra

\section{Ana Sofia Oliveira}

Instituto Universitário de Lisboa (ISCTE-IUL), DINÂMIA'CET

Avenida das Forças Armadas, Edifício ISCTE, 1649-026 Lisboa, Portugal

Contacto: ana.s.s.oliveira@gmail.com

\section{Pedro Quintela}

Centro de Estudos Sociais, Universidade de Coimbra

Colégio de S. Jerónimo, Largo D. Dinis, Apartado 3087, 3000-995 Coimbra, Portugal

Contacto: pedroquintela@ces.uc.pt

\section{Paula Guerra}

Faculdade de Letras da Universidade do Porto Via Panorâmica, s/n, 4150-564 Porto, Portugal Contacto: pguerra@letras.up.pt 
